\title{
Environmental Enrichment Modulates Drug Addiction and Binge-Like Consumption of Highly Rewarding Substances: A Role for Anxiety and Compulsivity Brain Systems?
}

OPEN ACCESS

Edited by:

David Belin,

University of Cambridge,

United Kingdom

Reviewed by:

Marco Venniro,

National Institute on Drug Abuse

(NIDA), United States

Christian P. Müller,

Friedrich-Alexander-Universität

Erlangen-Nürnberg, Germany

*Correspondence: Inmaculada Cubero

icubero@ual.es

Received: 24 September 2018 Accepted: 15 November 2018

Published: 29 November 2018

Citation:

Rodríguez-Ortega E and Cubero I (2018) Environmental Enrichment

Modulates Drug Addiction and Binge-Like Consumption of Highly Rewarding Substances: A Role for Anxiety and Compulsivity Brain Systems?

Front. Behav. Neurosci. 12:295. doi: 10.3389/fnbeh.2018.00295

\author{
Elisa Rodríguez-Ortega ${ }^{1}$ and Inmaculada Cubero ${ }^{1,2 *}$ \\ 'Departamento de Psicología, Universidad de Almería, Almería, Spain, ${ }^{2}$ Centro de Evaluación y Rehabilitación \\ Neuropsicológica (CERNEP), Universidad de Almería, Almería, Spain
}

Drug addiction is a chronic disorder comprising components of both impulsivity and compulsivity in the so called "addiction cycle" which develops over time from early non-dependent, repetitive, binge-consumption to later post-dependent compulsive consumption. Thus, frequent binge-like intake is a typical pattern of excessive drug intake characteristic of the pre-dependent phase of the addiction cycle, which represent an important risk factor to develop addiction in vulnerable individuals. In this framework, it is of paramount interest to further understand the earliest stage of the addiction cycle so novel approaches would emerge aimed to control repetitive episodes of bingeconsumption in non-dependent subjects, protecting vulnerable individuals from transition to dependence. Environmental enrichment (EE) is a preclinical animal model in which animals are housed under novel, social enriched conditions, which allows exercising and provides sensory and cognitive stimulation. EE promotes important improvements for a variety of cognitive processes and clear therapeutic and protective effects preventing ethanol $(\mathrm{EtOH})$ and drug addiction as well. Interestingly, recent observations suggest that EE might additionally modulate binge-like intake of highly palatable caloric substances, including $\mathrm{EtOH}$, which suggests the ability of $\mathrm{EE}$ to regulate consumption during the initial stage of the addiction cycle. We have proposed that EE protective and therapeutic effects on binge-consumption of palatable substances might primarily be mediated by the modulatory control that EE exerts on anxiety and impulsivity/compulsivity traits, which are all risk factors favoring transition to drug addiction.

Keywords: environmental enrichment, the addiction cycle, anxiety, impulsivity/compulsivity, binge-intake

\section{INTRODUCTION}

Drug addiction is a chronic psychiatric disorder which exhibits components of both impulsivity and compulsivity and develops over time on three progressive stages in the so called "addiction cycle" (Koob and Volkow, 2009): (1) a binge/intoxication phase guided by the rewarding properties of drugs and impulsivity; (2) a withdrawal phase where excessive consumption escalates; and (3) a preoccupation/anticipation phase mainly guided by negative reinforcement, increased stress and anxiety and compulsivity (Koob and Volkow, 2009). Similarly to drugs, recent growing scientific evidence points to the existence of the new disorder called "food addiction" which exhibits several 
neurobehavioral components matching drug addiction disorders (Avena et al., 2008; Gearhardt et al., 2011; Novelle and Diéguez, 2018), and where binge eating of highly palatable/caloric substances dominates the early stages of that process (Schulte et al., 2016).

Traditionally, drug and ethanol $(\mathrm{EtOH})$ addiction research is dominated by studies addressing post-dependent stages of the addiction cycle, modeled by drug/EtOH dependence (Yardley and Ray, 2016; Spanagel, 2017) and drug/EtOH relapse preclinical procedures (Marchant et al., 2013; Vengeliene et al., 2014). Because continued binge-like consumption represents a risk behavior that favors transition to addiction (Koob and Le Moal, 2006; Courtney and Polich, 2009; Crabbe et al., 2011; Thiele and Navarro, 2014), we have alternatively focused our interest during the last years in the early pre-dependent stage of the addiction cycle dominated by repetitive binge-like intake (Alcaraz-Iborra et al., 2014, 2017; Alcaraz-Iborra and Cubero, 2015; Carvajal et al., 2015; Rodríguez-Ortega et al., 2018). It is our, and others authors (Thiele and Navarro, 2014) believe, that understanding those neurobehavioral processes involved in repetitive binge consumption in non-dependent animals would help us to develop new approaches preventing transition to dependence. In this regard, we have recently addressed in our laboratory the beneficial impact of providing environmental enriched housing conditions to adolescent and adult animals showing spontaneous binge-like consumption.

It is well known that housing conditions modulate diverse psychological processes and drug addiction (Nithianantharajah and Hannan, 2006). Preclinical research have demonstrated that environmental enrichment (EE), where animals are socially grouped and exposed to sensorial and motor enriched housing conditions (Crofton et al., 2015), prevents and also modulates ongoing EtOH intake and drug addiction as well (Nithianantharajah and Hannan, 2006). Consistent with this work, we have recently extended this knowledge by showing the therapeutic and protective role of $\mathrm{EE}$ on excessive binge-like consumption of $\mathrm{EtOH}$ (Rodríguez-Ortega et al., 2018). Interestingly, there is experimental evidence indicating that EE exposure also reduces anxiety (Peña et al., 2006, 2009; Sztainberg et al., 2010; Rodríguez-Ortega et al., 2018), compulsivity (Muehlmann et al., 2012; Bechard et al., 2016; Rodríguez-Ortega et al., 2018) and modulates EtOH (Deehan et al., 2007, 2011; de Carvalho et al., 2010; Rodríguez-Ortega et al., 2018) and sucrose intake (Brenes and Fornaguera, 2008; Grimm et al., 2010, 2013, 2016). Elevated anxiety (Wand, 2005), high sensitivity to stress (Goeders, 2003) and/or high compulsivity (Figee et al., 2016) might significantly increase vulnerability to develop addiction; on the other hand, we have reported that EE modulate spontaneous binge-intake. Taking together the aforementioned data, we have proposed the working hypothesis that EE housing conditions might primarily act on anxiety and impulsivity/compulsivity related brain systems during the intoxication early phase of the addiction cycle, protecting vulnerable non-dependent organisms from excessive binge-like intake and transition to dependence (Rodríguez-Ortega et al., 2018).
In the next paragraphs we first address the impact of EE exposure on the later dependent stage of the addiction cycle and then, we focus on more recent evidence indicating the additional benefits of EE exposure on the early, binge-dominated, pre-dependent stage.

\section{ENVIRONMENTAL ENRICHMENT EXPOSURE REGULATES DRUG AND SUGAR INTAKE DURING THE LATER STAGE OF THE ADDICTION CYCLE}

\section{EE Protective Role in Drug Addiction}

Recent studies employing animal models firmly submit that EE access during adolescence could act as a protective tool to prevent drug addiction development (Stairs and Bardo, 2009; Solinas et al., 2010). C57BL/6J mice raised under EE conditions during adolescence showed attenuated morphine-induced conditioned place preference (CPP), reduced hyperlocomotion and behavioral sensitization induced by acute morphine administration (Xu et al., 2007), and also showed blunted acute morphine-induced locomotor activity (Xu et al., 2014). Furthermore, rearing C57BL/6J mice in EE conditions reduced the reinforcing properties of heroin in a CPP test (El Rawas et al., 2009) and reduced Sprague-Dawley rats' amphetamine self-administration (SA) in a fixed ratio (FR) paradigm (Green et al., 2002). Moreover, early EE access reduced cocaine rewarding properties in a CPP test, reduced cocaine induced motor activation, blunted responses to a repetitive cocaine challenge (Solinas et al., 2009) and decreased intravenous cocaine SA in C57BL/6J mice and Sprague-Dawley rats (Green et al., 2010).

\section{EE Therapeutic Role in Drug Addiction}

On the other hand, there is consistent scientific evidence supporting the therapeutic effect of EE access during adulthood to modulate drug consumption, drug reward and drug relapse. Thus, in Long Evans rats trained for continued heroin administration in a FR program, EE access blunted operant responses in cue-induced reinstatement of heroin seeking (Galaj et al., 2016). In Wistar rats, exposure to EE decreased behavioral deficits induced by methamphetamine and the risk of withdrawal unleashed by relapse (Hajheidari et al., 2015). EE also reduced heroin-, nicotin- and methamphetamine-seeking responses measured by a FR schedule in Sprague-Dawley rats (Sikora et al., 2018). Additionally, cocaine-induced behavioral sensitization and CPP to cocaine were blunted in adult $\mathrm{C} 57 \mathrm{BL} / 6$ mice exposed to EE conditions and $\mathrm{EE}$ also protected cocaine-pre-exposed animals from cocaine-elicited CPP reinstatement (Solinas et al., 2008). In Sprague-Dawley rats, EE access blunted cocaine and stress induced cocaine reinstatement (Chauvet et al., 2009). EE eliminated cocaineseeking induced by context in C57BL/6 mice (Chauvet et al., 2011) and blunted the onset of cocaine craving incubation. In the same direction, EE eliminated an already stablished cocaine incubation (Chauvet et al., 2012), reduced reinstatement of cocaine operant responding elicited by a sensorial cue and also 
inhibited cocaine-seeking responses during extinction (Thiel et al., 2009).

\section{EE Therapeutic Role on Sucrose Intake and Sucrose Seeking}

Interestingly, exposure to $\mathrm{EE}$ housing conditions do also modulate excessive consumption of highly palatable caloric substances. Isolated Sprague-Dawley rats consumed more sucrose than social or EE housed counterparts in a two bottlechoice (2BC) sucrose consumption test (Brenes and Fornaguera, 2008); isolated reared Lister hooded rats significantly drank more sucrose than socially reared rats when given sucrose in a $2 B C$ paradigm in an ascending order of presentation (Hall et al., 1997). Additionally, single housed Wistar rats showed greater CPP for sucrose than their socially housed counterparts (Van den Berg et al., 1999). Moreover, EE access after sucrose SA training decreased sucrose seeking in Long-Evans rats, as measured by the response for a tone plus light cue previously conditioned to sucrose SA (Grimm et al., 2010). Also, acute and chronic access to EE was effective in reducing sucrose cue-reactivity and consumption in Long-Evans rats (Grimm et al., 2013, 2016). And isolated Sprague-Dawley rats were more sensitive to a cue-light compound paired with sucrose, when compared with enriched housed rats (Gill and Cain, 2011). Finally, Sprague-Dawley rats under EE housing conditions showed greater extinction of sucrose-maintained operant responding on a continuous reinforcement schedule than isolated rats (Stairs et al., 2006). Taking together, available data indicate that $\mathrm{EE}$ access clearly regulates sucrose consumption and sucrose seeking.

\section{ENVIRONMENTAL ENRICHMENT EXPOSURE REGULATES BINGE-LIKE CONSUMPTION IN NON-DEPENDENT ANIMALS DURING THE EARLY STAGE OF THE ADDICTION CYCLE}

While there is consistent experimental evidence regarding the impact of EE on drug addiction, far less is known regarding the effect of EE exposure on excessive consumption of rewarding substances during early stages of the addiction cycle, dominated by binge-like intake. Preliminary data on $\mathrm{EtOH}$ research strongly suggest that $\mathrm{EE}$ exposure might provide therapeutic and protective effects to successfully modulate binge-like EtOH intake characteristic of the early stages of the addiction cycle. "Drinking in the dark" (DID; Rhodes et al., 2005, 2007) is a preclinical model of binge-like drinking which models human EtOH binge-intake as it triggers similar patterns of high voluntary EtOH consumption (BECs around $80 \mathrm{mg} / \mathrm{dl}$ ) in short intervals (Cox et al., 2013; Alcaraz-Iborra et al., 2014; Thiele and Navarro, 2014; Carvajal et al., 2015). DID also models human binge consumption of caloric palatable substances. Thus, sucrose limited access on a DID procedure triggers more sucrose intake than $50 \%$ of the total amount consumed over $24 \mathrm{~h}$ under unlimited access (Sparta et al., 2008; Kaur et al., 2012). Given the ability of DID to model human binge-like consumption, it has been employed for studying the impact of $\mathrm{EE}$ on binge-like consumption of $\mathrm{EtOH}$ and other rewarding substances (sucrose) during the initial stages of the addiction cycle.

\section{EE Reduces EtOH Binge-Like Consumption}

Recent evidence indicates that $\mathrm{EE}$ exposure might work to modulate excessive, binge-like $\mathrm{EtOH}$ consumption during the pre-dependent, early stage, of the addiction cycle. First, social and $\mathrm{EE}$ reduced EtOH preference and binge-like EtOH consumption in adult male C57BL/6 mice living in continuous $(24 \mathrm{~h})$ or restricted $(3 \mathrm{~h})$ EE conditions (Marianno et al., 2017). Also, C57BL/6 mice early socially housed showed reduced EtOH binge-like intake in a DID-2BC schedule when compared with their isolated housed counterparts (Lopez et al., 2011). EE access blunted high EtOH binge-like intake elicited by chronic social isolation in C57BL/6J mice (Lopez and Laber, 2015) and EE rearing during adolescence protected C57BL/6J mice from excessive EtOH binge-like drinking during adulthood (Rodríguez-Ortega et al., 2018). Furthermore, $\mathrm{EE}$ access significantly ameliorated steady EtOH binge-like consumption of adult mice housed in standard conditions (Rodríguez-Ortega et al., 2018) indicating a therapeutic role of $\mathrm{EE}$ on EtOH binge-like intake during that early, pre-dependent stage. Taking together, preliminary evidence points to the benefits of $\mathrm{EE}$ exposure, either during adolescence as a protective tool, or during adulthood as a therapeutic one, to modulate $\mathrm{EtOH}$ binge-like consumption in non-dependent organisms.

\section{ENVIRONMENTAL ENRICHMENT EXPOSURE MODULATES ANXIETY-LIKE RESPONSES AND COMPULSIVITY}

High compulsivity (Figee et al., 2016), enhanced anxiety (Wand, 2005) and novelty-seeking responses (Iacono et al., 2008; Montagud-Romero et al., 2014; Arenas et al., 2016) are all premorbid neurobehavioral traits strongly linked to enhanced vulnerability to the onset of drug, food and $\mathrm{EtOH}$ addiction. Importantly, there is consistent scientific evidence pointing to the EE ability to regulate anxiety- and compulsivity-like behaviors as well as novelty-seeking traits. Thus, exposure to EE housing conditions reduced anxiety-like behaviors as measured by the Elevated Plus Maze (EPM) in both rats and mice (Peña et al., 2006, 2009; Sztainberg et al., 2010; Ragu Varman and Rajan, 2015; Bahi, 2017b), the Zero Maze (EZM) in rats (Nobre, 2016) and the light/dark box in mice (Sztainberg et al., 2010; Ragu Varman and Rajan, 2015). Moreover, EE housing conditions decreased motor exploration in SHR rats in an open field test (de Carvalho et al., 2010) and did blunt the onset of repetitive compulsive motor responses (Muehlmann et al., 2012; Bechard and Lewis, 2016; Bechard et al., 2016), which has been considered a manifestation of compulsivity in drug addiction (Figee et al., 2016). Finally, we have recently reported that animals under $\mathrm{EE}$ and long-term exposed to EtOH binge-consumption, show reduced anxiety- and compulsive-like responses, and reduced 
novelty-seeking behaviors, as assessed by EPM and the Hole Board (HB) test, respectively (Rodríguez-Ortega et al., 2018).

Given that, first, EE protects and ameliorates excessive EtOH binge-like drinking (Lopez et al., 2011; Lopez and Laber, 2015; Marianno et al., 2017; Rodríguez-Ortega et al., 2018), excessive sucrose consumption (Brenes and Fornaguera, 2008; Grimm et al., 2010, 2013, 2016); and second, because EE reduces anxiety (Peña et al., 2006, 2009; Sztainberg et al., 2010; Ragu Varman and Rajan, 2015; Nobre, 2016; Bahi, 2017a; Rodríguez-Ortega et al., 2018) and compulsivity-like responses (Bechard and Lewis, 2016; Bechard et al., 2016; Rodríguez-Ortega et al., 2018), we have proposed the hypothesis holding the existence of a causal nexus linking EE-mediated reduced anxiety/compulsivity and reduced EtOH binge-like consumption. Thus, we defend a primary impact of EE on anxiety/compulsivity/impulsivity brain systems during the pre-dependent early stages of the addiction cycle which, in turn might secondarily modulate binge-like intake of rewarding substances, finally preventing transition to addiction in vulnerable organisms.

\section{ENVIRONMENTAL ENRICHMENT AND HUMAN DRUG INTAKE}

Consistent with preclinical results, human research has suggested that EE exposure during the early and later, stages of the addiction cycle might be determinant to control excessive drug intake and prevent drug relapse. In this regard, community programs such as the Strategic Prevention Framework (SPF), has successfully controlled elevated EtOH binge drinking in adolescents and enforcement outcomes overtime (AndersonCarpenter et al., 2016). Accordingly, the importance of controlling key environmental factors to prevent repetitive $\mathrm{EtOH}$ binge drinking episodes among students has been highlighted in national laws and drug policies, normative campaigns and targeted law enforcement (Clapp and Shillington, 2001; Clapp et al., 2003). Interestingly, programs such as Alcoholic Anonymous which encourage a controlled environment, free of drugs-cues and stress, together with enhanced social cognition and reinforcement (Schnabel, 2009), or the "Drug courts" program, which offers community-based treatment options (Turner et al., 2002), have both shown the utility of EE conditions to prevent EtOH relapse in addicted persons. Altogether, pre-clinical studies and human research, reinforce the idea that exposure to environmental enriched conditions during the different stages of the addiction cycle offer clear benefits to prevent and modulate binge-consumption, drug addiction and drug relapse.

Nevertheless, this is a young scientific field and we have a long way ahead. We need to further explore neurobehavioral and neurochemical mechanisms involved in EE positive effects, both protective and therapeutic, on the addiction cycle. We need to address whether EE exposure to non-addicted organisms impact

\section{REFERENCES}

Alcaraz-Iborra, M., and Cubero, I. (2015). Do Orexins contribute to impulsivitydriven binge consumption of rewarding stimulus and transition to drug/food on impulsive/compulsive consumption of also on other still non-explored drugs, during early stages of the addiction cycle, so new behavioral strategies can be developed to prevent transition to dependence. We need to further explore whether EE benefits on drug intake are primarily linked to EE-induced regulation of impulsivity/compulsivity and anxiety brain systems. We also need to understand how EE exposure during adolescence prevents during adulthood drug intake in different stages of the addiction cycle. Importantly, the role of EE on eating disorders and food addiction need to be deeply explored. In this regard, we are currently addressing in our lab whether EE exposure regulates binge-consumption of highly palatable caloric substances in non-dependent animals, so we can build testable hypothesis regarding the protector and therapeutic role of $\mathrm{EE}$ on the development of binge- and eating disorders and obesity. Finally, a new research avenue in this field, providing a better knowledge of EE neurochemical mechanisms, would help to develop new pharmacological modulators that mimic (environmimetics) or enhance EE positive effects (Nithianantharajah and Hannan, 2006).

\section{CONCLUSION}

Preclinical studies and human research suggest that EE has a therapeutic and a protective role in drug addiction and exerts a modulatory control on excessive binge-like intake of palatable substances, including EtOH and sucrose. We know that EE also regulates excessive anxiety and compulsivity/impulsivity-like behaviors, known to be risk factors favoring the development of binge-consumption and transition to addiction. In this framework, we have proposed the working hypothesis that EE exposure might primarily modulate anxiety and impulsivity/compulsivity brain systems which, in turn, might secondarily moderate binge consumption of palatable substances preventing the progression toward addictive consumption during later stages of the addiction cycle. Future studies will further elucidate whether the observed EE therapeutic and protective effect on binge-consumption and anxiety/impulsivity/compulsivity, are causally linked.

\section{AUTHOR CONTRIBUTIONS}

IC and ER-O designed the conceptual framework in the manuscript and wrote the manuscript. All authors critically reviewed the content and approved the final version for publication.

\section{FUNDING}

This work was supported by FEDER co-funding and Ministerio de Economia y Competitividad (Spain; grant PSI2015-64460-R to IC); Feder grant FEDERUALM05-23-006 (to IC).

dependence? Pharmacol. Biochem. Behav. 134, 31-34. doi: 10.1016/j.pbb.2015. 04.012

Alcaraz-Iborra, M., Carvajal, F., Lerma-Cabrera, J. M., Miguel, L., and Cubero, I. (2014). Binge-like consumption of caloric and non-caloric palatable substances 
in ad libitum-fed C57BL/6J mice: pharmacological and molecular evidence of orexin involvement. Behav. Brain Res. 272, 93-99. doi: 10.1016/j.bbr.2014. 06.049

Alcaraz-Iborra, M., Navarrete, F., Rodríguez-Ortega, E., de la Fuente, L., Manzanares, J., and Cubero, I. (2017). Different molecular/behavioral endophenotypes in $\mathrm{C} 57 \mathrm{BL} / 6 \mathrm{~J}$ mice predict the impact of $\mathrm{OX}_{1}$ receptor blockade on binge-like ethanol intake. Front. Behav. Neurosci. 11:186. doi: 10.3389/fnbeh.2017.00186

Anderson-Carpenter, K. D., Watson-Thompson, J., Chaney, L., and Jones, M. (2016). Reducing binge drinking in adolescents through implementation of the strategic prevention framework. Am. J. Community Psychol. 57, 36-46. doi: 10.1002/ajcp.12029

Arenas, M. C., Aguilar, M. A., Montagud-Romero, S., Mateos-García, A., NavarroFrancés, C. I., Miñarro, J., et al. (2016). Influence of the novelty-seeking endophenotype on the rewarding effects of psychostimulant drugs in animal models. Curr. Neuropharmacol. 14, 87-100. doi: 10.2174/1570159x1366615 0921112841

Avena, N. M., Rada, P., and Hoebel, B. G. (2008). Evidence for sugar addiction: behavioral and neurochemical effects of intermittent, excessive sugar intake. Neurosci. Biobehav. Rev. 32, 20-39. doi: 10.1016/j.neubiorev.2007.04.019

Bahi, A. (2017a). Decreased anxiety, voluntary ethanol intake and ethanol-induced CPP acquisition following activation of the metabotropic glutamate receptor 8 "mGluR8". Pharmacol. Biochem. Behav. 155, 32-42. doi: 10.1016/j.pbb.2017. 03.004

Bahi, A. (2017b). Environmental enrichment reduces chronic psychosocial stress-induced anxiety and ethanol-related behaviors in mice. Prog. Neuropsychopharmacol. Biol. Psychiatry 77, 65-74. doi: 10.1016/j.pnpbp. 2017.04.001

Bechard, A. R., Cacodcar, N., King, M. A., and Lewis, M. H. (2016). How does environmental enrichment reduce repetitive motor behaviors? Neuronal activation and dendritic morphology in the indirect basal ganglia pathway of a mouse model. Behav. Brain Res. 299, 122-131. doi: 10.1016/j.bbr.2015. 11.029

Bechard, A. R., and Lewis, M. H. (2016). Transgenerational effects of environmental enrichment on repetitive motor behavior development. Behav. Brain Res. 307, 145-149. doi: 10.1016/j.bbr.2016.04.005

Brenes, J. C., and Fornaguera, J. (2008). Effects of environmental enrichment and social isolation on sucrose consumption and preference: associations with depressive-like behavior and ventral striatum dopamine. Neurosci. Lett. 436, 278-282. doi: 10.1016/j.neulet.2008.03.045

Carvajal, F., Alcaraz-Iborra, M., Lerma-Cabrera, J. M., Valor, L. M., de la Fuente, L., Sanchez-Amate Mdel, C., et al. (2015). Orexin receptor 1 signaling contributes to ethanol binge-like drinking: pharmacological and molecular evidence. Behav. Brain Res. 287, 230-237. doi: 10.1016/j.bbr.2015. 03.046

Chauvet, C., Goldberg, S. R., Jaber, M., and Solinas, M. (2012). Effects of environmental enrichment on the incubation of cocaine craving. Neuropharmacology 63, 635-641. doi: 10.1016/j.neuropharm.2012.05.014

Chauvet, C., Lardeux, V., Goldberg, S. R., Jaber, M., and Solinas, M. (2009). Environmental enrichment reduces cocaine seeking and reinstatement induced by cues and stress but not by cocaine. Neuropsychopharmacology 34, 2767-2778. doi: 10.1038/npp.2009.127

Chauvet, C., Lardeux, V., Jaber, M., and Solinas, M. (2011). Brain regions associated with the reversal of cocaine conditioned place preference by environmental enrichment. Neuroscience 184, 88-96. doi: 10.1016/j. neuroscience.2011.03.068

Clapp, J. D., Lange, J., Jon, W. M., Shillington, A., Johnson, M., and Voas, R. (2003). Two studies examining environmental predictors of heavy drinking by college students. Prev. Sci. 4, 99-108. doi: 10.1023/A:10229742 15675

Clapp, J. D., and Shillington, A. M. (2001). Environmental predictors of heavy episodic drinking. Am. J. Drug Alcohol Abuse 27, 301-313. doi: 10.1081/ADA100103711

Courtney, K. E., and Polich, J. (2009). Binge drinking in young adults: data, definitions, and determinants. Psychol. Bull. 135, 142-156. doi: 10.103 7/a0014414

Cox, B. R., Olney, J. J., Lowery-Gionta, E. G., Sprow, G. M., Rinker, J. A., Navarro, M., et al. (2013). Repeated cycles of binge-like ethanol
(EtOH)-drinking in male C57BL/6J mice augments subsequent voluntary EtOH intake but not other dependence-like phenotypes. Alcohol. Clin. Exp. Res. 37, 1688-1695. doi: 10.1111/acer.12145

Crabbe, J. C., Harris, R. A., and Koob, G. F. (2011). Preclinical studies of alcohol binge drinking. Ann. N Y Acad. Sci. 1216, 24-40. doi: 10.1111/j.1749-6632.2010. 05895.x

Crofton, E. J., Zhang, Y., and Green, T. A. (2015). Inoculation stress hypothesis of environmental enrichment. Neurosci. Biobehav. Rev. 49, 19-31. doi: 10.1016/j. neubiorev.2014.11.017

de Carvalho, C. R., Pandolfo, P., Pamplona, F. A., and Takahashi, R. N. (2010). Environmental enrichment reduces the impact of novelty and motivational properties of ethanol in spontaneously hypertensive rats. Behav. Brain Res. 208, 231-236. doi: 10.1016/j.bbr.2009.11.043

Deehan, G. A., Cain, M. E., and Kiefer, S. W. (2007). Differential rearing conditions alter operant responding for ethanol in outbred rats. Alcohol. Clin. Exp. Res. 31, 1692-1698. doi: 10.1111/j.1530-0277.2007.00466.x

Deehan, G. A. Jr., Palmatier, M. I., Cain, M. E., and Kiefer, S. W. (2011). Differential rearing conditions and alcohol-preferring rats: consumption of and operant responding for ethanol. Behav. Neurosci. 125, 184-193. doi: $10.1037 / \mathrm{a} 0022627$

El Rawas, R., Thiriet, N., Lardeux, V., Jaber, M., and Solinas, M. (2009). Environmental enrichment decreases the rewarding but not the activating effects of heroin. Psychopharmacology 203, 561-570. doi: 10.1007/s00213-008$1402-6$

Figee, M., Pattij, T., Willuhn, I., Luigjes, J., van den Brink, W., Goudriaan, A., et al. (2016). Compulsivity in obsessive-compulsive disorder and addictions. Eur. Neuropsychopharmacol. 26, 856-868. doi: 10.1016/j.euroneuro.2015. 12.003

Galaj, E., Manuszak, M., and Ranaldi, R. (2016). Environmental enrichment as a potential intervention for heroin seeking. Drug Alcohol Depend. 163, 195-201. doi: 10.1016/j.drugalcdep.2016.04.016

Gearhardt, A., White, M., and Potenza, M. (2011). Binge eating disorder and food addiction. Curr. Drug Abus. Rev. 4, 201-207. doi: 10.2174/18744737111040 30201

Gill, M. J., and Cain, M. E. (2011). Effects of satiety on operant responding in rats raised in enrichment. Behav. Pharmacol. 22, 40-48. doi: 10.1097/fbp. 0b013e3283425a 86

Goeders, N. E. (2003). The impact of stress on addiction. Eur. Neuropsychopharmacol. 13, 435-441. doi: 10.1016/s0924-977x(03) 90003-4

Green, T. A., Alibhai, I. N., Roybal, C. N., Winstanley, C. A., Theobald, D. E. H., Birnbaum, S. G., et al. (2010). Environmental enrichment produces a behavioral phenotype mediated by low cyclic adenosine monophosphate response element binding (CREB) activity in the nucleus accumbens. Biol. Psichiatry 67, 28-35. doi: 10.1016/j.biopsych.2009. 06.022

Green, T. A., Gehrke, B. J., and Bardo, M. T. (2002). Environmental enrichment decreases intravenous amphetamine self-administration in rats: dose-response functions for fixed- and progressive-ratio schedules. Psychopharmacology 162, 373-378. doi: 10.1007/s00213-002$1134-\mathrm{y}$

Grimm, J. W., Barnes, J. L., Koerber, J., Glueck, E., Ginder, D., Hyde, J., et al. (2016). Effects of acute or chronic environmental enrichment on regional Fos protein expression following sucrose cue-reactivity testing in rats. Brain Struct. Funct. 221, 2817-2830. doi: 10.1007/s00429-0151074-z

Grimm, J. W., Osincup, D., Wells, B., Manaois, M., Fyall, A., Buse, C., et al. (2010). Environmental enrichment attenuates cue-induced reinstatement of sucrose seeking in rats. Behav. Pharmacol. 19, 777-785. doi: 10.1097/fbp. 0b013e32831c3b18

Grimm, J. W., Weber, R., Barnes, J., Koerber, J., Dorsey, K., and Glueck, E. (2013). Brief exposure to novel or enriched environments reduces sucrose cue-reactivity and consumption in rats after 1 or 30 days of forced abstinence from self-administration. PLoS One 8:e54164. doi: 10.1371/journal.pone. 0054164

Hajheidari, S., Miladi-Gorji, H., and Bigdeli, I. (2015). Effect of the environmental enrichment on the severity of psychological dependence and voluntary methamphetamine consumption in methamphetamine 
withdrawn rats. Neurosci. Lett. 584, 151-155. doi: 10.1016/j.neulet.2014. 10.017

Hall, F. S., Humby, T., Wilkinson, L. S., and Robbins, T. W. (1997). The effects of isolation-rearing on sucrose consumption in rats. Physiol. Behav. 62, 291-297. doi: 10.1016/s0031-9384(97)00116-9

Iacono, W. G., Malone, S. M., and McGue, M. (2008). Behavioral disinhibition and the development of early-onset addiction: common and specific influences. Annu. Rev. Clin. Psychol. 4, 325-348. doi: 10.1146/annurev.clinpsy.4.022007. 141157

Kaur, S., Li, J., Stenzel-Poore, M. P., and Ryabinin, A. E. (2012). Corticotropinreleasing factor acting on corticotropin-releasing factor receptor type 1 is critical for binge alcohol drinking in mice. Alcohol. Clin. Exp. Res. 36, 369-376. doi: 10.1111/j.1530-0277.2011.01610.x

Koob, G. F., and Le Moal, M. (Eds). (2006). "What is Addiction?," in Neurobiology of Addiction, (Cambridge, CA: Academic Press), 1-22. doi: 10.151 5/9781400868568-016

Koob, G. F., and Volkow, N. D. (2009). Neurocircuitry of addiction. Neuropsychopharmacology 35, 217-238. doi: 10.1038/bjp.2008.51

Lopez, M. F., Doremus-Fitzwater, T. L., and Becker, H. C. (2011). Chronic social isolation and chronic variable stress during early development induce later elevated ethanol intake in adult C57BL/6J mice. Alcohol 45, 355-364. doi: 10.1016/j.alcohol.2010.08.017

Lopez, M. F., and Laber, K. (2015). Impact of social isolation and enriched environment during adolescence on voluntary ethanol intake and anxiety in C57BL/6J mice. Physiol. Behav. 148, 151-156. doi: 10.1016/j.physbeh.2014. 11.012

Marchant, N. J., Li, X., and Shaham, Y. (2013). Recent developments in animal models of drug relapse. Curr. Opin. Neurobiol. 23, 675-683. doi: 10.1016/j.conb. 2013.01.003

Marianno, P., Abrahao, K. P., and Camarini, R. (2017). Environmental enrichment blunts ethanol consumption after restraint stress in C57BL/6 mice. PLoS One 12:e0170317. doi: 10.1371/journal.pone.0170317

Montagud-Romero, S., Daza-Losada, M., Vidal-Infer, A., Maldonado, C., Aguilar, M. A., Miñarro, J., et al. (2014). The novelty-seeking phenotype modulates the long-lasting effects of intermittent ethanol administration during adolescence. PLoS One 9:e92576. doi: 10.1371/journal.pone.00 92576

Muehlmann, A. M., Edington, G., Mihalik, A. C., Buchwald, Z., Koppuzha, D., Korah, M., et al. (2012). Further characterization of repetitive behavior in C58 mice: developmental trajectory and effects of environmental enrichment. Behav. Brain Res. 235, 143-149. doi: 10.1016/j.bbr.2012. 07.041

Nithianantharajah, J., and Hannan, A. J. (2006). Enriched environments, experience-dependent plasticity and disorders of the nervous system. Nat. Rev. Neurosci. 7, 697-709. doi: 10.1038/nrn1970

Nobre, M. (2016). Environmental enrichment may protect against neural and behavioural damage caused by withdrawal from chronic alcohol intake. Int. J. Dev. Neurosci. 55, 15-27. doi: 10.1016/j.ijdevneu.2016. 09.003

Novelle, M. G., and Diéguez, C. (2018). Food addiction and binge eating: lessons learned from animal models. Nutrients 10:E71. doi: 10.3390/nu100 10071

Peña, Y., Prunell, M., Dimitsantos, V., Nadal, R., and Escorihuela, R. (2006). Environmental enrichment effects in social investigation in rats are gender dependent. Behav. Brain Res. 174, 181-187. doi: 10.1016/j.bbr.2006. 07.007

Peña, Y., Prunell, M., Rotllant, D., Armario, A., and Escorihuela, R. M. (2009). Enduring effects of environmental enrichment from weaning to adulthood on pituitary-adrenal function, pre-pulse inhibition and learning in male and female rats. Psychoneuroendocrinology 34, 1390-1404. doi: 10.1016/j.psyneuen. 2009.04.019

Ragu Varman, D., and Rajan, K. E. (2015). Environmental enrichment reduces anxiety by differentially activating serotonergic and neuropeptide y (NPY)ergic system in Indian field mouse (Mus booduga): an animal model of post-traumatic stress disorder. PLoS One 10:e127945. doi: 10.1371/journal. pone. 0127945

Rhodes, J. S., Best, K., Belknap, J. K., Finn, D. A., and Crabbe, J. C. (2005). Evaluation of a simple model of ethanol drinking to intoxication in C57BL/6J mice. Physiol. Behav. 84, 53-63. doi: 10.1016/j.physbeh.2004. 10.007

Rhodes, J. S., Ford, M. M., Yu, C.-H., Brown, L. L., Finn, D. A., Garland, T. Jr., et al. (2007). Mouse inbred strain differences in ethanol drinking to intoxication. Genes Brain Behav. 6, 1-18. doi: 10.1111/j.1601-183x.2006. 00210.x

Rodríguez-Ortega, E., de la Fuente, L., de Amo, E., and Cubero, I. (2018), Environmental enrichment during adolescence acts as a protective and therapeutic tool for ethanol binge-drinking, anxiety-like, novelty seeking and compulsive-like behaviors in C57BL/6J mice during adulthood. Front. Behav. Neurosci. 12:177. doi: 10.3389/fnbeh.2018.00177

Schnabel, J. (2009). Rethinking rehab. Nature 458, 25-27. doi: 10.1038/45 $8025 \mathrm{a}$

Schulte, E. M., Grilo, C. M., Gearhardt, A. N., Arbor, A., States, U., Haven, N., et al. (2016). Shared and unique mechanisms underlying binge eating disorder and addictive disorders. Clin. Psychol. Rev. 44, 125-139. doi: 10.1016/j.cpr.2016. 02.001

Sikora, M., Nicolas, C., Istin, M., Jaafari, N., Thiriet, N., and Solinas, M. (2018). Generalization of effects of environmental enrichment on seeking for different classes of drugs of abuse. Behav. Brain Res. 341, 109-113. doi: 10.1016/j.bbr. 2017.12.027

Solinas, M., Chauvet, C., Thiriet, N., El Rawas, R., and Jaber, M. (2008). Reversal of cocaine addiction by environmental enrichment. Proc. Natl. Acad. Sci. U S A 105, 17145-17150. doi: 10.1073/pnas.0806889105

Solinas, M., Thiriet, N., El Rawas, R., Lardeux, V., and Jaber, M. (2009). Environmental enrichment during early stages of life reduces the behavioral, neurochemical and molecular effects of cocaine. Neuropsychopharmacology 34 , 1102-1111. doi: 10.1038/npp.2008.51

Solinas, M., Thiriet, N., Chauvet, C., and Jaber, M. (2010). Prevention and treatment of drug addiction by environmental enrichment. Prog. Neurobiol. 92, 572-592. doi: 10.1016/j.pneurobio.2010.08.002

Spanagel, R. (2017). Animal models of addiction. Dialogues Clin. Neurosci. 19, $247-258$.

Sparta, D. R., Sparrow, A. M., Lowery, E. G., Fee, J. R., Knapp, D. J., and Thiele, T. E. (2008). Blockade of the corticotropin releasing factor type 1 receptor attenuates elevated ethanol drinking associated with drinking in the dark procedures. Alcohol. Clin. Exp. Res. 32, 259-265. doi: 10.1111/j.1530-0277. 2007.00575.x

Stairs, D. J., and Bardo, M. T. (2009). Neurobehavioral effects of environmental enrichment and drug abuse vulnerability. Pharmacol. Biochem. Behav. 92, 377-382. doi: 10.1016/j.pbb.2009.01.016

Stairs, D. J., Klein, E. D., and Bardo, M. T. (2006). Effects of environmental enrichment on extinction and reinstatement of amphetamine selfadministration and sucrose-maintained responding. Behav. Pharmacol. 17, 597-604. doi: 10.1097/01.fbp.0000236271.72300.0e

Sztainberg, Y., Kuperman, Y., Tsoory, M., Lebow, M., and Chen, A. (2010). The anxiolytic effect of environmental enrichment is mediated via amygdalar CRF receptor type 1. Mol. Psychiatry 15, 905-917. doi: 10.1038/mp. 2009.151

Thiele, T. E., and Navarro, M. (2014). "Drinking in the dark" (DID) procedures: a model of binge-like ethanol drinking in non-dependent mice. Alcohol 48 , 235-241. doi: 10.1016/j.alcohol.2013.08.005

Thiel, K. J., Sanabria, F., Pentkowski, N. S., and Neisewander, J. L. (2009). Anticraving effects of environmental enrichment. Int. J. Neuropsychopharmacol. 12, 1151-1156. doi: 10.1017/S1461145709990472

Turner, S., Longshore, D., Wenzel, S., Deschenes, E., Greenwood, P., Fain, T., et al. (2002). A decade of drug treatment court research. Subst. Use Misuse 37 1489-1527. doi: 10.1081/JA-120014420

Van den Berg, C. L., Pijlman, F. T. A., Koning, H. A. M., Diergaarde, L., Van Ree, J. M., and Spruijt, B. M. (1999). Isolation changes the incentive value of sucrose and social behaviour in juvenile and adult rats. Behav. Brain Res. 106, 133-142. doi: 10.1016/s0166-4328(99)00099-6

Vengeliene, V., Bilbao, A., and Spanagel, R. (2014). The alcohol deprivation effect model for studying relapse behavior: a comparison between rats and mice. Alcohol 48, 313-320. doi: 10.1016/j.alcohol.2014.03.002

Wand, G. (2005). The anxious amygdala: CREB signaling and predisposition to anxiety and alcoholism. J. Clin. Invest. 115, 2697-2699. doi: 10.1172/jci 26436 
Xu, J., Sun, J., Xue, Z., and Li, X. (2014). An enriched environment reduces the stress level and locomotor activity induced by acute morphine treatment and by saline after chronic morphine treatment in mice. Neuroreport 25, 701-709. doi: 10.1097/wnr.0000000000000164

Xu, Z., Hou, B., Gao, Y., He, F., and Zhang, C. (2007). Effects of enriched environment on morphine-induced reward in mice. Exp. Neurol. 204, 714-719. doi: 10.1016/j.expneurol.2006.12.027

Yardley, M. M., and Ray, L. A. (2016). Medications development for the treatment of alcohol use disorder: insights into the predictive value of animal and human laboratory models. Addict. Biol. 22, 581-615. doi: 10.1111/adb. 12349
Conflict of Interest Statement: The authors declare that the research was conducted in the absence of any commercial or financial relationships that could be construed as a potential conflict of interest.

Copyright (c) 2018 Rodríguez-Ortega and Cubero. This is an open-access article distributed under the terms of the Creative Commons Attribution License (CC BY). The use, distribution or reproduction in other forums is permitted, provided the original author(s) and the copyright owner(s) are credited and that the original publication in this journal is cited, in accordance with accepted academic practice. No use, distribution or reproduction is permitted which does not comply with these terms. 